\title{
Genetics and Biochemistry of Flower Color in Stokes Aster
}

\author{
Jessica G. Barb ${ }^{1}$ \\ Department of Horticultural Science, North Carolina State University, Campus Box 7609, \\ Raleigh, NC 27695-7609 \\ Dennis J. Werner ${ }^{2,4}$ \\ Department of Horticultural Science, North Carolina State University, Campus Box 7522, \\ Raleigh, NC 27695-7522 \\ Robert J. Griesbach ${ }^{3}$ \\ Floral and Nursery Plant Research, U.S. National Arboretum, U.S. Department of Agriculture, \\ Agricultural Research Service, BARC-West, Building 010A, Beltsville, MD 20705
}

\begin{abstract}
AdDitional INDEX words. Recessive epistasis, flavonoid biosynthesis, luteolin, petunidin, cyanidin, flavone, albescent, Stokesia laevis

Abstract. Stokes aster [Stokesia laevis (J. Hill) Greene] is a herbaceous perennial endemic to the coastal plains of the southeastern United States. Anthocyanin and copigment aglycones from flowers were characterized using highperformance liquid chromatography. Blue, lavender, violet, and albescent flowers each contained the anthocyanidin petunidin, although albescent flowers contained a substantially smaller amount. Pale pink flowers were found to contain only cyanidin. Anthocyanins and carotenoids were not present in pale yellow flowers of this species. All flowers contained the flavone luteolin. Genetic analysis of $\mathrm{F}_{1}, \mathrm{~F}_{2}$, and $\mathrm{BC}_{1}$ populations suggested that flower color in stokes aster is controlled by at least three loci. $F_{2}$ populations of blue $\times$ albescent and blue $\times$ pale yellow flowering plants segregated in a 3:1 ratio of blue to albescent or pale yellow flowered progeny, indicating that albescent and pale yellow flower colors were recessive and each controlled by a single locus with two alleles. $\mathrm{BC}_{1}$ populations supported these results. We propose the symbols $A$ and $Y: A A$ and $Y Y$ plants synthesize a normal amount of anthocyanins, $a a$ plants synthesize a reduced amount of anthocyanins, and $y y$ plants do not synthesize anthocyanins. When the two mutant phenotypes (i.e., albescent $[a a]$ and pale yellow $[y y]$ ) were crossed, the $F_{1} s$ were blue, and the $F_{2}$ segregated in a 9 blue:3 albescent: 4 yellow ratio, indicating that the recessive locus $(y)$, when homozygous, was epistatic to other loci involved in anthocyanin production (e.g., $A$ ), and that the genotypes of the parents used in these crosses were $a a Y Y$ (albescent) and $A A y y$ (pale yellow). $\mathrm{F}_{1}, \mathrm{~F}_{2}$, and $\mathrm{BC}_{1}$ populations of blue (petunidin) $\times$ pale pink (cyanidin) flowering plants revealed that cyanidin production was recessive and controlled by a single locus, $P$, with two alleles, whereby $P P$ plants synthesize petunidin and $p p$ plants synthesize cyanidin. It was difficult to distinguish albescent- and pale pink-flowered progeny in segregating generations, therefore three genetic models were proposed and tested to determine the genotype(s) (i.e., AApp, Aapp, or aapp) of the pale pink-flowered plants. Based on these analyses, we propose a theoretical biochemical pathway for flavonoid biosynthesis in stokes aster.
\end{abstract}

Flavonoids, carotenoids, and betalains are three classes of pigments that produce flower color in plants. Of these pigments, flavonoids are the most abundant and responsible for a broad range of flower colors, including pale yellow, ivory, pink, magenta, red, blue, and violet. Flavonoids can be divided into two groups: copigments (e.g., flavanones, flavones, and chalcones) and anthocyanins (e.g., petunidin, pelargonidin, and cyanidin; Griesbach, 2005; Griesbach and Batdorf, 1995). Anthocyanins accumulate in vacuoles of epidermal or subepidermal cells and produce pink, magenta, red, blue, and violet flowers. Copigments are also sequestered in the vacuole, but generally produce pale yellow, ivory, near-white, or colorless flowers in the absence of other pigments. In many instances, flower color is correlated with the type(s) of anthocyanidin(s)

Received for publication 22 Jan. 2008. Accepted for publication 7 Apr. 2008. The authors gratefully acknowledge the technical assistance of Layne Snelling and the staff at the Horticulture Field Labs and the Sandhills Research Station. ${ }^{1}$ Graduate student.

${ }^{2}$ Director, JC Raulston Arboretum.

${ }^{3}$ Research Geneticist.

${ }^{4}$ Corresponding author. E-mail: dennis_werner@ncsu.edu. (i.e., anthocyanin without sugars) present. However, abiotic factors (e.g., light intensity, temperature, and water stress) also influence flower color (Ben-Meir et al., 2002; Winkel-Shirley, 2002). In addition, biotic factors, including vacuolar $\mathrm{pH}$, the presence of metal ions, copigmentation, and cell shape, also affect flower color (Ben-Meir et al., 2002; Griesbach, 1997; Noda et al., 1994; Shiono et al., 2005; Waterworth and Griesbach, 2001; Yabuya et al., 2000).

The biochemical and genetic basis of flavonoid biosynthesis is described for many plant species (for reviews, see Bohm, 1998; Holton and Cornish, 1995; Winkel-Shirley, 2001). Many genes that encode enzymes specific to flavonoid biosynthesis have been identified, and flower color in several model species is now associated with differences in single genes (for reviews, see Forkmann, 1991; Gerats and Martin, 1992; Holton and Cornish, 1995; Griesbach, 2005; Wiering and de Vlaming, 1984). Numerous structural and regulatory genes have been cloned, characterized, and used in transformation experiments to alter flower color in a variety of species (for reviews, see Chandler and Lu, 2005; Courtney-Gutterson, 1994; Davies and Schwinn, 1997; Forkmann and Martens, 2001; Mol et al., 1999; 
Schijlen et al., 2004; Tanaka et al., 2005). Epistatic interactions among flavonoid genes are common (Conner and Erickson, 1991; Fick, 1976; Hawkins and Dane, 2001; Pahlavani et al., 2004; Tyrach and Horn, 1997) because several key enzymes in the flavonoid biosynthetic pathway have multiple precursors.

The genus Stokesia (J. Hill) Greene is a member of the Asteraceae family and contains a single species, S. laevis, common name "stokes aster." Stokes aster is native to the southeastern United States (Bailey, 1949; Gunn and White, 1974) and is classified as cold hardy, Department of Agriculture zones 5 through 8(9) (Gettys and Werner, 2002; Nau, 1996; Still, 1994). Stokes aster is a herbaceous perennial grown primarily for its large aster-like flowers that are typically blue or lavender, however, taxa also exist with violet, pale yellow, pale pink, or albescent flowers. Cultivated forms include 'Alba' and 'Silver Moon' (nearly white flowers with a trace of color, especially in the disk florets), 'Colorwheel' (pale pink flowers), 'Mary Gregory' (pale yellow flowers), 'Peachies Pick' (lavender flowers), 'Honeysong Purple', and 'Purple Parasols' (violet flowers), as well as 'Omega Skyrocket' and 'Blue Danube' (blue flowers). Most cultivated forms of stokes aster are diploid ( $2 n=2 x=14$; Gunn and White, 1974; Jones, 1974). Nearly all cultivars of stokes aster were selected from natural populations, gardens, or nursery production fields, thus a formal pedigree is lacking for these cultivars. The current understanding of the genetics and biochemistry of flower color of stokes aster is limited (Bohm and Stuessy, 2001; Gettys, 2000; Harborne and Williams, 1977). A more complete understanding of the biochemistry and genetics of flower color for this species would greatly facilitate the development of improved cultivars. This study characterizes the biochemical basis of blue, lavender, violet, albescent, pale pink, and pale yellow flowers and proposes a genetic model for the inheritance of flower color in stokes aster. In addition, a biochemical pathway for flavonoid biosynthesis in stokes aster is presented.

\section{Materials and Methods}

Plant material. Ten selections of stokes aster were examined, including taxa with albescent ('Alba' and 'Silver Moon'), pale pink (NC-Maroon and 'Colorwheel'), pale yellow ('Mary Gregory'), violet ('Honeysong Purple' and 'Purple Parasols'), lavender ('Peachies Pick'), and blue flowers ('Omega Skyrocket' and 'Blue Danube'). All cultivars of stokes aster were acquired and maintained as asexually propagated clones with the exceptions of 'Omega Skyrocket' and 'Alba', which were produced from seed. Plants used in this study were obtained from our breeding collection except for 'Omega Skyrocket', which was acquired from Jelitto Seed Co. (Schwarmstedt, Germany).

Tissue Collection And extraction. Flavonoids were extracted from frozen flower tissue (1-3 g fresh weight) with $20 \mathrm{~mL}$ of $1 \% \mathrm{HCl}$ in methanol, filtered, and reduced to dryness at $40{ }^{\circ} \mathrm{C}$ under vacuum, resuspended in $\approx 10 \mathrm{~mL}$ of $100 \%$ ethanol, dried, and resuspended in a minimal volume of $1 \% \mathrm{HCl}$ in methanol. Flower tissue was also extracted in $100 \%$ chloroform to release carotenoid pigments. Because no carotenoid pigments were detected, further purification and analysis were not necessary.

Flavonoid analysis. Flavonoids were characterized using high-resolution, high-performance liquid chromatography (HPLC) as previously described (Griesbach et al., 1991).
Pigment preparations were acid hydrolyzed at $100{ }^{\circ} \mathrm{C}$ in $3 \mathrm{~N}$ $\mathrm{HCl}$ for $30 \mathrm{~min}$ and separated on a $7.8 \times 300 \mathrm{~mm}$ Bondapak C18 column (Waters, Milford, MA) using a 20-min linear gradient of $0 \%$ to $15 \%(\mathrm{v} / \mathrm{v})$ acetonitrile in aqueous $1.5 \%(\mathrm{v} / \mathrm{v})$ phosphoric acid and $15 \%(\mathrm{v} / \mathrm{v})$ acetic acid. The column was then washed with $15 \%(\mathrm{v} / \mathrm{v})$ acetonitrile for an additional 20 min. The flow rate was $1.0 \mathrm{~mL} \cdot \mathrm{min}^{-1}$ and detection was by absorption at $540 \mathrm{~nm}$. Copigment aglycones were analyzed in a similar manner as the anthocyanidins (Griesbach and Asen, 1990). The only differences were in HPLC elution buffer $(1 \%$ triethylamine at $\mathrm{pH} 3.0)$, gradient $(0 \%$ to $20 \%$ [v/v] linear gradient in $20 \mathrm{~min}$ with a hold at $20 \%$ [v/v] for an additional 20 $\mathrm{min})$, and detection wavelength $(340 \mathrm{~nm})$. Isolated compounds (i.e., anthocyanidins and copigment aglycones) were characterized by coelution with known standards previously purified from other species.

INHERITANCE ANALYsis. All $\mathrm{F}_{1}$ and $\mathrm{BC}_{1}$ hybridizations were made using a camel's hair paintbrush on plants grown in greenhouses at North Carolina State University (NCSU), Raleigh. Daytime temperatures in the greenhouse ranged from $25{ }^{\circ} \mathrm{C}$ to $35{ }^{\circ} \mathrm{C}$, and plants were fertilized daily with 100 $\left(\mathrm{mg} \cdot \mathrm{L}^{-1}\right) \mathrm{N}$ Peters $20 \mathrm{~N}-8.7 \mathrm{P}-16.6 \mathrm{~K}$ General Purpose or Peters EXCEL Cal-Mag 15N-2.2P-12.5K fertilizer (Scotts Co., Marysville, $\mathrm{OH}$ ). Flowers were pollinated once daily for 4 to 5 consecutive days. All taxa used in this study were presumed self-sterile except for 'Alba' (Gettys and Werner, 2002), therefore emasculation was not performed. Because $F_{1}$ progeny were also presumed to be self-sterile, $F_{2}$ populations were created by intercrossing 8 to 15 full-sibling $F_{1}$ plants using native insect activity in isolation blocks located at the NCSU Sandhills Research Station in Jackson Springs, NC. Isolation blocks were spaced at least $500 \mathrm{~m}$ apart to prevent crosspollination among blocks.

Previous research showed that seeds of stokes aster do not require stratification to germinate, (Gettys and Werner, 2002), therefore unstratified seeds were sown into $115-\mathrm{cm}^{3}$ elongated tree tubes (RLC-7 Super "Stubby" Cells; Stuewe and Sons, Corvallis, OR) filled with Fafard No. 4-P potting medium (Conrad Fafard, Agawam, MA). Seeds germinated and grew for $\approx 5$ months in the greenhouse before they were planted in the field (NCSU Horticultural Field Laboratory, Raleigh or the NCSU Sandhills Research Station) or transplanted into 3.8-L pots containing Fafard No. 4-P potting medium and grown on an outdoor gravel pad (NCSU Horticultural Field Laboratory). Progeny were visually evaluated for flower color and were assigned to a phenotypic class (e.g., blue, lavender, purple, albescent, pale yellow, pale pink, or orchid). Chi-square tests for goodness-of-fit to classical phenotypic ratios were used to analyze data from segregating populations. Data were pooled from similar populations if the chi-square test for homogeneity indicated an absence of heterogeneity (Strickberger, 1976).

\section{Results and Discussion}

\section{Anthocyanidin identification}

Anthocyanidin profiles for blue ('Omega Skyrocket' and 'Blue Danube'), lavender ('Peachies Pick'), and violet ('Honeysong Purple' and 'Purple Parasols') flowers each displayed a single identical peak (Fig. 1, A and I, Table 1). This unknown peak coeluted with petunidin when a standard solution (i.e., petunidin, peonidin, and pelargonidin) was coinjected, and was therefore characterized as petunidin (Fig. 1, A-C). These 


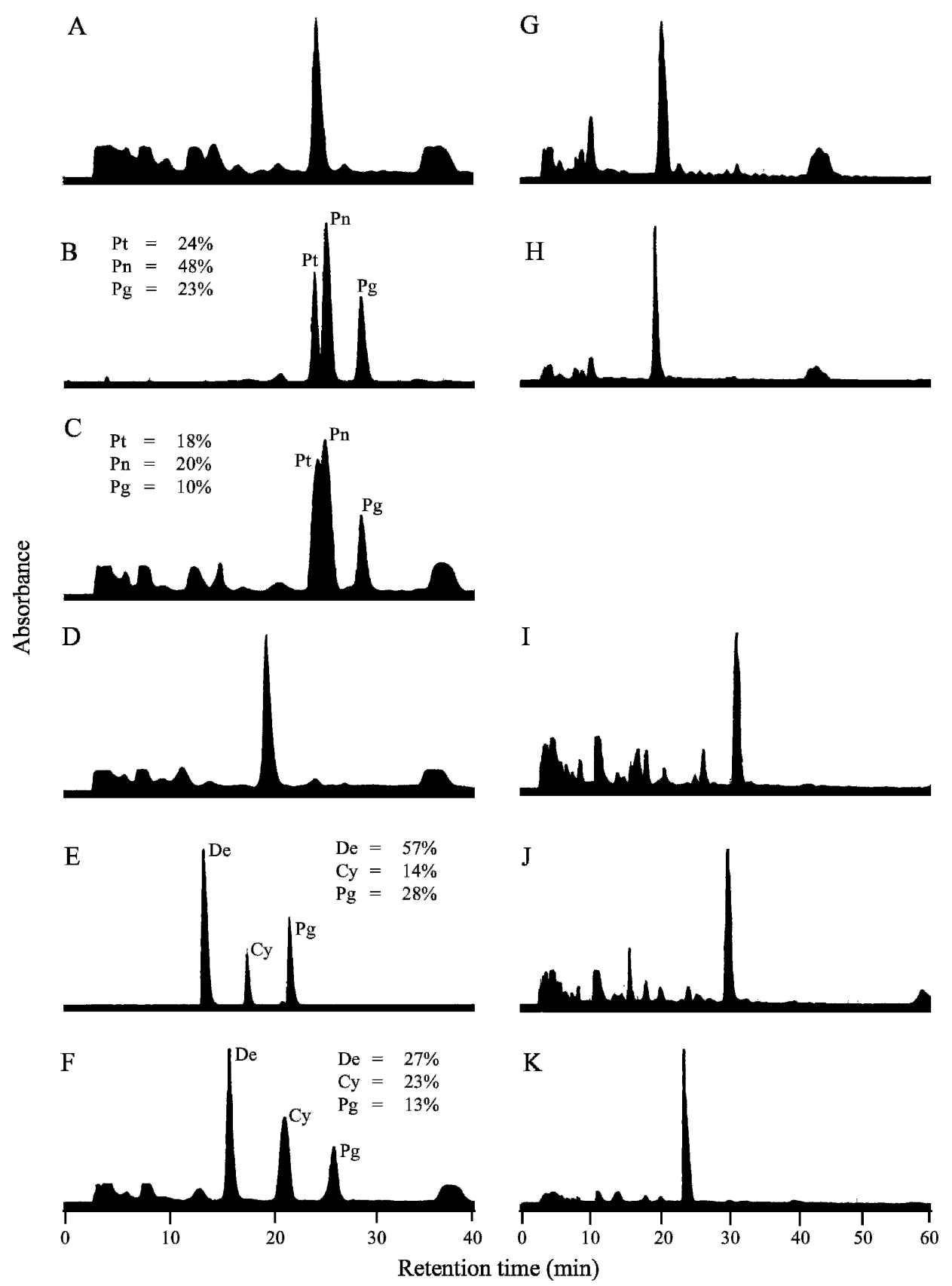

Fig. 1. HPLC profile of anthocyanidins extracted from flowers of stokes aster. (A) 'Purple Parasols', (B) standard solution of petunidin, peonidin, and pelargonidin, $(\mathbf{C})$ coinjection of A and B, (D) NC-Maroon, (E) standard solution of delphinidin, cyanidin, and pelargonidin, (F) coinjection of D and E, (G) 'Colorwheel', (H) coinjection of $G$ and a standard solution of cyanidin, (I) 'Peachies Pick', (J) $F_{1}$ of 'Peachies Pick' $\times$ 'Colorwheel', and $(\mathbf{K})$ 'Colorwheel'. Peak areas are measured as a percentage of the total and are included for the major peaks in $\mathrm{B}, \mathrm{C}, \mathrm{E}$, and $\mathrm{F}$. $\mathrm{Pt}=$ petunidin, $\mathrm{Pn}=$ peonidin, $\mathrm{Pg}=$ pelgargonidin, $\mathrm{De}=$ delphinidin, $\mathrm{Cy}=$ cyanidin.

results suggest that differences in flower color (i.e., blue, lavender, and violet) in these taxa are not due to differences in anthocyanidin, but instead may be attributable to differences in concentration, copigmentation, vacuolar $\mathrm{pH}$, glycosylation, acylation, or the influence of metal ions (for review, see Forkmann, 1991). The anthocyanidin profile for albescent flowers ('Alba') indicated that flowers of this cultivar also contain petunidin, although at a substantially lower amount (data not shown). These results suggest that 'Alba' produces anthocyanins and is appropriately characterized as an albescent mutant, which produces $1 \%$ to $25 \%$ of the pigment expected in a normal cyanic (i.e., anthocyanin-producing) type, rather than an alba mutant, which is devoid of pigmentation (Griesbach and Klein, 1993). Anthocyanidin profiles for pale pink flowers (NC-Maroon and 'Colorwheel') were identical and contained a single peak (Fig. 1, D and $\mathrm{K})$. Using coelution with a known standard (i.e., delphinidin, cyanidin, and pelargonidin), this peak was characterized as cyanidin (Fig. 1, D-F). No evidence of petunidin or another anthocyanidin was detected in these samples. Pigment profiles of flowers from $F_{1}$ hybrids of $\mathrm{NC}$ Maroon (cyanidin) $\times$ 'Honeysong Purple' (petunidin) and 'Peachies Pick' (petunidin) $\times$ 'Colorwheel' (cyanidin), each had a single identical peak that was characterized as petunidin (Fig. 1I-K). No evidence of cyanidin was observed in either sample. These results agree with the findings of the inheritance study (this study, data not shown), which suggests that blue, lavender, and violet flowers containing petunidin are completely dominant in the $\mathrm{F}_{1}$ generation to pale pink flowers containing cyanidin. Analysis indicated that pale yellow flowers ('Mary Gregory') do not contain carotenoids and also lack anthocyanins (data not shown).

\section{Copigment identification}

Aglycone copigment profiles for blue, lavender, violet, albescent, pale pink, and pale yellow flowers were similar and contained a single peak. This peak was identified as the copigment luteolin as judged by coelution with known standards (Fig. 2, Table 1) and ultraviolet spectroscopy (data not shown). Evidence of additional flavonoid aglycones (e.g., dihydroquercetin, dihydromyricetin, etc.) was not found in these samples.

Results indicate that pale yellow flowers of stokes aster ('Mary Gregory') contain only the copigment luteolin (Fig. 2E). Luteolin as an aglycone (i.e., without sugar moieties) is colorless in vivo. However, some forms of luteolin such as 2'hydroxyluteolin (i.e., isoetin, 5,7,2',4',5' -pentahydroxyflavone later determined to be 7'-gycosides) are yellow and are found in flowers of some members of the Cichorieae tribe (Asteraceae) (Bohm and Stuessy, 2001; Forkmann, 1991; Harborne, 1978, 1991). Because our samples were acid-hydrolyzed before analysis, we could not ascertain whether the luteolin isolated 
Table 1. Anthocyanidin and luteolin composition of flowers of stokes aster as determined using HPLC.

\begin{tabular}{llccc}
\hline & \multicolumn{1}{c}{$\begin{array}{c}\text { Flower } \\
\text { color }\end{array}$} & \multicolumn{3}{c}{ Pigment $^{\mathrm{z}}$} \\
\cline { 2 - 5 } Sample & \multicolumn{1}{c}{ Petunidin } & Cyanidin & Luteolin \\
\hline Omega Skyrocket & Blue & + & - & + \\
Blue Danube & Blue & + & - & n.d. ${ }^{\mathrm{y}}$ \\
Peachies Pick & Lavender & + & - & + \\
Honeysong Purple & Violet & + & - & + \\
Purple Parasols & Violet & + & - & + \\
Alba & Albescent & trace & - & + \\
Silver Moon & Albescent & n.d. & n.d. & n.d. \\
Mary Gregory & Pale yellow & - & - & + \\
Colorwheel & Pale pink & - & + & n.d. \\
NC-Maroon & Pale pink & - & + & + \\
Peachies Pick $\times$ & Lavender & + & - & n.d. \\
$\quad$ Colorwheel & & & & \\
NC-Maroon $\times$ & Violet & + & - & n.d. \\
$\quad$ Honeysong & & & & \\
$\quad$ Purple & & & & \\
Mary Gregory $\times$ & Violet & & & \\
$\quad$ Omega & & & & \\
Skyrocket & & & &
\end{tabular}

${ }^{z_{+}}=$present,$-=$absent.

${ }^{\mathrm{y}}$ n.d. $=$ not determined.

from 'Mary Gregory' was modified (i.e., acylation or glycosylation) and were thus responsible for producing the pale yellow flower color observed in this cultivar. Other research has shown that yellow flower color can be produced when colorless pigments are compartmentalized in the cytoplasm, not in the vacuole, where they form dense aggregations on the surface of a cytoplasmic protein matrix (Markham et al., 2001). Thus, it is also possible that a similar complex of luteolin molecules is responsible for producing pale yellow flowers in this species.

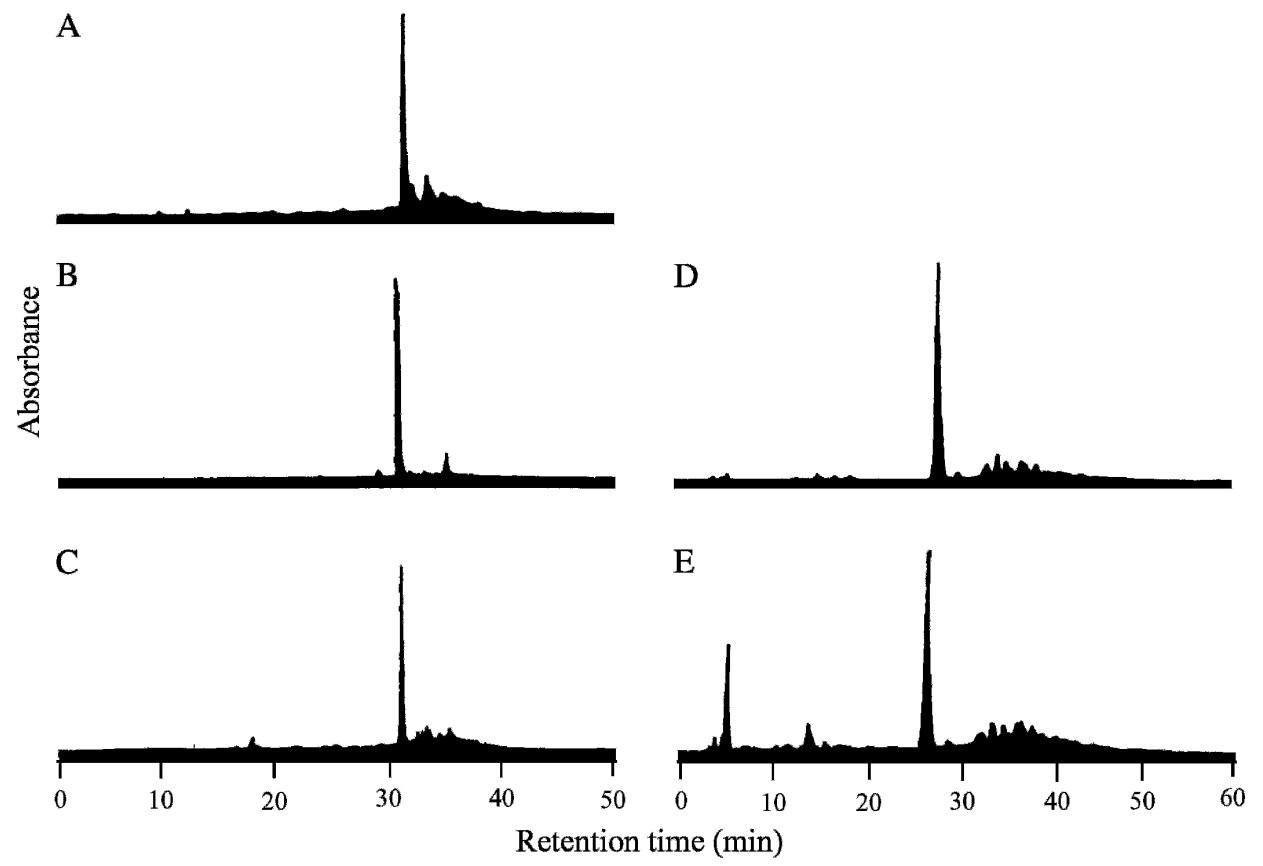

Fig. 2. HPLC profile of aglycone copigments extracted from flowers of stokes aster. (A) NC-Maroon, (B) standard solution of luteolin, (C) coinjection of A and B, (D) 'Purple Parasols', and (E) 'Mary Gregory'.

\section{Inheritance analysis}

Inheritance of flower color was investigated using 'Peachies Pick' (lavender flowers), 'Blue Danube' (blue flowers), 'Purple Parasols' (violet flowers), 'Alba' and 'Silver Moon' (albescent flowers), 'Colorwheel' and NC-Maroon (pale pink flowers), 'Mary Gregory' (pale yellow flowers), and some of their $F_{1}, F_{2}$, and $\mathrm{BC}_{1}$ families. Because blue, lavender, and violet flowers have similar anthocyanidin profiles, as shown by this study, they are henceforth freely interchangeable in the context of these genetic analyses.

Blue $\times$ Albescent. Previous work demonstrated that blue, lavender, and violet flowers (containing wild-type levels of petunidin; this work) were dominant in the $\mathrm{F}_{1}$ generation to pale yellow, albescent, and pale pink flowers (containing no anthocyanins, reduced levels of petunidin, or cyanidin instead of petunidin, respectively) (Gettys and Werner, 2002). $\mathrm{F}_{2}$ progeny of 'Alba' (albescent) $\times$ 'Blue Danube' (blue), and 'Alba' (albescent) $\times$ 'Peachies Pick' (lavender) families segregated 3 blue/lavender: 1 albescent $\left(\chi^{2}=0.005, P=0.942\right)$, suggesting that albescent flower color is recessive and controlled by a single locus with two alleles (Table 2). This conclusion was supported by the segregation in $\mathrm{BC}_{1}$ populations of 'Peachies Pick' $\times($ 'Peachies Pick' $\times$ 'Alba') and ('Peachies Pick' $\times$ 'Alba' $) \times$ 'Alba' $\left(\chi^{2}=0.000, P=1.000\right.$ and $\chi^{2}=0.407, P=$ 0.523 , respectively; Table 2). Recovery of albescent-flowered progeny in the $\mathrm{BC}_{1}$ population of ('Peachies Pick' $\times$ 'Alba') $\times$ 'Peachies Pick' is likely the result of self-pollination (Table 2). We recommend designating this locus " $A$." We propose that $A$ has two alleles and demonstrates complete dominance; plants with the $A A$ or $A a$ genotype are blue, lavender, or violet flowered and plants with the $a a$ genotype are albescent flowered. Based on the biochemical analysis of these phenotypes presented earlier, we conclude that the wild-type form of this locus (A) allows for the normal synthesis and accumulation of petunidin and the copigment luteolin, and the mutant form $(a)$ reduces the synthesis or accumulation of both of these compounds.

Blue $\times$ Pale Yellow. Progeny of three $F_{2}$ families of 'Peachies Pick' (lavender) $\times$ 'Mary Gregory' (pale yellow) segregated in a 3:1 ratio of lavender- to pale yellowflowered progeny $\left(\chi^{2}=3.939, P=\right.$ 0.047 ), suggesting that yellow flower color is recessive and controlled by a single locus with two alleles, for which we propose the symbol " $Y$." Plants with the $Y Y$ or $Y y$ genotype are blue, lavender, or violet flowered and contain petunidin and luteolin, and plants with the $y y$ genotype are pale yellow flowered and only contain luteolin. Based on the biochemical analysis of the phenotypes presented in this work, we conclude that the dominant or wild-type form of this locus $(Y)$ allows for the normal synthesis of anthocyanins, in this case, petunidin, and the recessive mutant form of this locus $(y)$ prevents the synthesis or accumulation of all 
Table 2. Segregation of flower color in $F_{2}$ and $\mathrm{BC}_{1}$ families of stokes aster. Blue and lavender flowers are phenotypically and biochemically similar, therefore, they were combined for analysis and designated as "blue."

\begin{tabular}{lrccccc}
\hline & \multicolumn{5}{c}{ Flower color } & Expected \\
Population & ratio & $\chi^{2}$ & $P$ \\
\cline { 2 - 4 } Blue $\times$ Albescent & Blue & Albescent & Yellow & & & \\
$\mathrm{F}_{2} \mathrm{~A} \times \mathrm{BD}$ and $\mathrm{A} \times \mathrm{P}^{\mathrm{y}}$ & 537 & 178 & 0 & $3: 1$ & 0.005 & 0.942 \\
$\mathrm{BC}_{1}(\mathrm{P} \times \mathrm{A}) \times \mathrm{P}$ & 297 & $8^{\mathrm{x}}$ & 0 & $1: 0$ & - & - \\
$\mathrm{BC}_{1}(\mathrm{P} \times \mathrm{A}) \times \mathrm{A}^{\mathrm{w}}$ & 154 & 143 & 0 & $1: 1$ & 0.407 & 0.523 \\
$\mathrm{BC}_{1} \mathrm{P} \times(\mathrm{P} \times \mathrm{A})$ & 85 & 0 & 0 & $1: 0$ & 0.000 & 1.000 \\
$\mathrm{Blue} \times \mathrm{Yellow}$ & & & & & & \\
$\mathrm{F}_{2} \mathrm{P} \times \mathrm{MG}^{\mathrm{v}}$ & 1184 & 0 & 350 & $3: 1$ & 3.939 & 0.047 \\
$\mathrm{BC}_{1} \mathrm{MG} \times(\mathrm{P} \times \mathrm{MG})$ & 36 & 0 & 41 & $1: 1$ & 0.325 & 0.569 \\
$\mathrm{BC}_{1}(\mathrm{P} \times \mathrm{MG}) \times \mathrm{MG}$ & 229 & 0 & 175 & $1: 1$ & 7.218 & 0.007 \\
$\mathrm{BC}_{1} \mathrm{P} \times(\mathrm{P} \times \mathrm{MG})$ & 8 & 0 & 0 & $1: 0$ & - & - \\
$\mathrm{BC}_{1}(\mathrm{P} \times \mathrm{MG}) \times \mathrm{P}$ & 60 & 0 & $6^{\mathrm{y}}$ & $1: 0$ & - & - \\
\hline
\end{tabular}

${ }^{\mathrm{z}} \mathrm{A}=$ 'Alba', $\mathrm{BD}=$ 'Blue Danube', $\mathrm{P}=$ 'Peachies Pick', MG = 'Mary Gregory'.

${ }^{\mathrm{y}} \mathrm{Chi}$-square test for homogeneity $\left(\chi^{2}=0.052, P=0.820\right)$.

${ }^{\mathrm{x}}$ Aberrant progeny likely the result of self-pollination.

${ }^{\mathrm{w}}$ Chi-square test for homogeneity $\left(\chi^{2}=0.203, P=0.652\right)$.

${ }^{\mathrm{v}}$ Chi-square test for homogeneity $\left(\chi^{2}=2.116, P=0.347\right)$.

anthocyanins. These results were supported by the segregation in the $\mathrm{BC}_{1}$ population of 'Mary Gregory' $\times$ ('Peachies Pick' $\times$ 'Mary Gregory'; $\left.\chi^{2}=0.325, P=0.569\right)$ and the $\mathrm{BC}_{1}$ population of 'Peachies Pick' $\times$ ('Peachies Pick' $\times$ 'Mary Gregory'; $\chi^{2}=$ $0.000, P=1.000$ ) (Table 2). Recovery of pale yellow-flowered progeny in the $\mathrm{BC}_{1}$ population of ('Peachies Pick' $\times$ 'Mary Gregory') $\times$ 'Peachies Pick' is likely attributable to some selffertility of the $F_{1}$ female. Likewise, the poor fit to the expected 1:1 ratio of blue- and pale yellow-flowered progeny in the $\mathrm{BC}_{1}$ population of ('Peachies Pick' $\times$ 'Mary Gregory') $\times$ 'Mary Gregory' $\left(\chi^{2}=7.218, P=0.007\right)$ is also likely due to self-fertility of the $\mathrm{F}_{1}$ female (Table 2). Interestingly, a $\mathrm{BC}_{1}$ population with a segregation ratio of one pale yellowflowered progeny for every 10 lavenderflowered progeny (i.e., 60 lavender: 6 pale yellow) indicates that the $F_{1}$ female ('Peachies Pick' $\times$ 'Mary Gregory') in this cross likely produced selfed progeny $\approx 40 \%$ of the time. Based on this calculation, we reexamined the $\mathrm{BC}_{1}$ population of ('Peachies Pick' $\times$ 'Mary Gregory') $\times$ 'Mary Gregory', now taking into consideration the presumption that the $\mathrm{F}_{1}$ female produced self progeny $40 \%$ of the time and found that the "adjusted" expected ratio of 242.4 lavender: 161.6 yellow $\left(\chi^{2}=1.852\right.$, $P=0.174)$ versus 202 lavender:202 yellow $\left(\chi^{2}=7.218, P=0.007\right)$ provided a better fit to the observed data.

Albescent $\times$ Pale Yellow. $F_{2}$ progeny derived from the hybridizations of 'Alba' (albescent) $\times$ 'Mary Gregory' (pale yellow) and 'Mary Gregory' (pale yellow) $\times$ 'Silver Moon' (albescent) and 'Alba' (albescent) were evaluated to examine the possible interaction between $A$ and $Y$. Flowers from 1261 $\mathrm{F}_{2}$ plants were visually examined and partitioned into three phenotypic classes: 729 blue

${ }^{\mathrm{z}} \mathrm{A}=$ 'Alba', $\mathrm{MG}=$ 'Mary Gregory'. or lavender (normal anthocyanins), 254 albescent (reduced anthocyanins), and 278 pale yellow (no anthocyanins). Segregation was tested for goodness-of-fit to expected ratios of $9: 3: 4$ and $9: 3: 3$. Both hypotheses assume that $Y$, in the homozygous recessive state $(y y)$, blocks the synthesis of anthocyanins and is epistatic to $A$, but the 9:3:3 ratio also assumes that the double recessive genotype (aayy) is lethal.

The observed ratio did not fit the expected 9:3:4 ratio $\left(\chi^{2}=6.252, P=0.044\right)$ and only weakly fit the 9:3:3 ratio $\left(\chi^{2}=3.659, P=\right.$ $0.160)$ (Table 3). Test crosses where yellowflowered plants randomly selected from these $\mathrm{F}_{2}$ populations (presumed to have genotypes of AAyy, Aayy, or aayy) were crossed with 'Alba' (presumed to have the aaYY genotype) revealed that the double recessive genotype (aayy) was viable and that of the 13 yellow $\mathrm{F}_{2} \mathrm{~s}$ tested four were AAyy, five were Aayy, and four were aayy (Table 3). Interestingly, these $\mathrm{F}_{2} \mathrm{~s}$ displayed levels of self-fertility ranging from $0 \%$ to $36.9 \%$. Based on the results of these test crosses, we propose that the hypothesis of recessive epistasis without lethality (i.e., 9:3:4) is more appropriate even though the data does not fit a 9:3:4 ratio. Furthermore, we believe that the deficit in the observed number of yellow-flowered plants ( 278 observed vs. 315.25 expected) is due in part to the absence of anthocyanins in the leaves, root, and stems of the

Table 3. Segregation of flower color in $\mathrm{F}_{2}$ and $\mathrm{BC}_{1}$ families of stokes aster. Blue and lavender flowers are phenotypically and biochemically similar, therefore, they were combined for analysis and designated as "blue."

\begin{tabular}{|c|c|c|c|c|c|c|}
\hline \multirow[b]{2}{*}{ Population $^{z}$} & \multicolumn{3}{|c|}{ Flower color } & \multirow{2}{*}{$\begin{array}{c}\text { Expected } \\
\text { Ratio }\end{array}$} & \multirow[b]{2}{*}{$\chi^{2}$} & \multirow[b]{2}{*}{$P$} \\
\hline & Blue & Albescent & Yellow & & & \\
\hline \multicolumn{7}{|l|}{ Yellow $\times$ Albescent } \\
\hline $\mathrm{F}_{2}$ Total $^{\mathrm{y}}$ & 729 & 254 & 278 & $9: 3: 4$ & 6.252 & 0.044 \\
\hline $\mathrm{F}_{2}$ Total $^{\mathrm{x}}$ & 729 & 254 & 278 & $9: 3: 3$ & 3.659 & 0.160 \\
\hline $\mathrm{BC}_{1} \mathrm{~A} \times(\mathrm{A} \times \mathrm{MG})$ & 130 & 118 & 0 & $1: 1: 0$ & 0.581 & 0.446 \\
\hline $\mathrm{BC}_{1} \mathrm{MG} \times(\mathrm{A} \times \mathrm{MG})$ & 18 & 0 & 15 & $1: 0: 1$ & 0.273 & 0.602 \\
\hline $\mathrm{BC}_{1}(\mathrm{MG} \times \mathrm{A}) \times \mathrm{MG}$ & 2 & 0 & 1 & $1: 0: 1$ & 0.333 & 0.564 \\
\hline $\mathrm{BC}_{1}(\mathrm{~A} \times \mathrm{MG}) \times \mathrm{A}$ & 110 & 94 & $3^{w}$ & $1: 1: 0$ & 1.255 & 0.262 \\
\hline $\mathrm{BC}_{1}(\mathrm{~A} \times \mathrm{MG}) \times \mathrm{MG}$ & 78 & $3^{w}$ & 53 & $1: 0: 1$ & 4.771 & 0.029 \\
\hline $\mathrm{TC}_{1}\left(\right.$ yellow $\left.\mathrm{F}_{2} \times \mathrm{A}\right)$ & 101 & 0 & $6^{\mathrm{w}}$ & $1: 0: 0$ & - & - \\
\hline $\mathrm{TC}_{3}\left(\right.$ yellow $\left.\mathrm{F}_{2} \times \mathrm{A}\right)$ & 41 & 0 & $24^{\mathrm{w}}$ & $1: 0: 0$ & - & - \\
\hline $\mathrm{TC}_{14}\left(\right.$ yellow $\left.\mathrm{F}_{2} \times \mathrm{A}\right)$ & 53 & 0 & $1^{\mathrm{w}}$ & $1: 0: 0$ & - & - \\
\hline $\mathrm{TC}_{28}\left(\right.$ yellow $\left.\mathrm{F}_{2} \times \mathrm{A}\right)$ & 58 & $1^{\mathrm{w}}$ & 0 & 1:0:0 & - & - \\
\hline $\mathrm{TC}_{4}\left(\right.$ yellow $\left.\mathrm{F}_{2} \times \mathrm{A}\right)$ & 85 & 66 & $15^{\mathrm{w}}$ & $1: 1: 0$ & 2.391 & 0.122 \\
\hline $\mathrm{TC}_{6}\left(\right.$ yellow $\left.\mathrm{F}_{2} \times \mathrm{A}\right)$ & 21 & 18 & $1^{\mathrm{w}}$ & $1: 1: 0$ & 0.231 & 0.631 \\
\hline $\mathrm{TC}_{13}\left(\right.$ yellow $\left.\mathrm{F}_{2} \times \mathrm{A}\right)$ & 10 & 6 & $4^{w}$ & $1: 1: 0$ & 1.000 & 0.317 \\
\hline $\mathrm{TC}_{16}\left(\right.$ yellow $\left.\mathrm{F}_{2} \times \mathrm{A}\right)$ & 12 & 10 & $1^{\mathrm{w}}$ & $1: 1: 0$ & 0.181 & 0.671 \\
\hline $\mathrm{TC}_{21}\left(\right.$ yellow $\left.\mathrm{F}_{2} \times \mathrm{A}\right)$ & 48 & 41 & $6^{\mathrm{w}}$ & $1: 1: 0$ & 0.551 & 0.458 \\
\hline $\mathrm{TC}_{2}\left(\right.$ yellow $\left.\mathrm{F}_{2} \times \mathrm{A}\right)$ & 0 & 118 & 0 & $0: 1: 0$ & - & - \\
\hline $\mathrm{TC}_{5}\left(\right.$ yellow $\left.\mathrm{F}_{2} \times \mathrm{A}\right)$ & $1^{\mathrm{w}}$ & 27 & 0 & $0: 1: 0$ & - & - \\
\hline $\mathrm{TC}_{7}\left(\right.$ yellow $\left.\mathrm{F}_{2} \times \mathrm{A}\right)$ & 0 & 31 & $2^{\mathrm{w}}$ & $0: 1: 0$ & - & - \\
\hline $\mathrm{TC}_{22}\left(\right.$ yellow $\left.\mathrm{F}_{2} \times \mathrm{A}\right)$ & 0 & 73 & $1^{\mathrm{w}}$ & $0: 1: 0$ & - & - \\
\hline
\end{tabular}

${ }^{\mathrm{y}} \mathrm{Chi}$-square test for homogeneity $\left(\chi^{2}=7.651, P=0.054\right)$.

${ }^{\mathrm{x}}$ Chi-square test for homogeneity $\left(\chi^{2}=6.803, P=0.078\right)$.

${ }^{\mathrm{w}}$ Aberrant progeny are likely the result of self-pollination. 
yellow-flowered plants, possibly making them less viable, especially during periods of stress (e.g., extreme temperatures, drought, high light, etc.; for reviews, see Gould, 2004; Harborne and Williams, 2000; Steyn et al., 2002; WinkelShirley, 2002). Linkage between $A$ and $Y$ could not be ascertained due to the epistatic nature of the homozygous recessive condition of $Y$.

Progeny of $\mathrm{BC}_{1}$ populations of 'Alba' $\times($ 'Alba' $\times$ 'Mary Gregory'), 'Mary Gregory' $\times$ ('Alba' $\times$ 'Mary Gregory'), and ('Mary Gregory' $\times$ 'Alba') $\times$ 'Mary Gregory' closely matched expected ratios of $1: 1$ blue and albescent $\left(\chi^{2}=0.581, P=0.446\right)$ and $1: 1$ blue and pale yellow $\left(\chi^{2}=0.273, P=0.602 ; \chi^{2}=0.333\right.$, $P=0.564$ ), respectively (Table 3 ). $\mathrm{BC}_{1}$ progeny from an ('Alba' $\times$ 'Mary Gregory') $\times$ 'Alba' population fit the expected segregation ratio of $1: 1$ blue and albescent $\left(\chi^{2}=1.255, P=\right.$ 0.262 ), however, $\mathrm{BC}_{1}$ progeny from a population of ('Alba' $\times$ 'Mary Gregory') $\times$ 'Mary Gregory' did not fit the expected segregation ratio of 1:1 blue and pale yellow $\left(\chi^{2}=4.771, P=\right.$ 0.029; Table 3). The higher number of blue-flowered progeny and the lower numbers of albescent- and pale yellow-flowered progeny coupled with the unexpected recovery of two pale yellow- and three albescent-flowered progeny in these $\mathrm{BC}_{1}$ populations suggest that the female plant in these crosses ('Alba' $\times$ 'Mary Gregory') is nominally self-fertile. This assumption was confirmed in previous work, which determined that $F_{1}$ progeny of 'Alba' $\times$ 'Mary Gregory' were slightly self-fertile (Gettys and Werner, 2002). Based on these findings, we excluded populations derived from crosses using an $\mathrm{F}_{1}$ of 'Alba' $\times$ 'Mary Gregory' as the female parent from the overall analysis.

Lavender $\times$ Pale Pink. $F_{1}$ progeny produced by crosses between two pale pink-flowering taxa ('Colorwheel' and NCMaroon) were pink flowered, indicating that these two taxa were allelic for pink flower color (data not shown). $F_{1}$ progeny of 'Peachies Pick' (petunidin) and NC-Maroon and 'Colorwheel' (cyanidin) were lavender flowered and contained only petunidin, indicating that the pale pink (cyanidin-containing) phenotype, is completely recessive. Progeny from $\mathrm{F}_{2}$ populations of 'Peachies Pick' $\times$ NC-Maroon and 'Colorwheel' were blue, purple, albescent, or pink flowered. In this genetic background, it was difficult to distinguish between pale pinkand albescent-flowered progeny, therefore these phenotypic classes were combined and progeny were categorized as pale pink or albescent versus blue or purple. Unfortunately, because the pale pink and albescent phenotypes could not be distinguished, it was impossible to separate the possible contribution of $A$, which reduces pigmentation, from the contribution of another locus(loci), which control(s) whether cyanidin is produced instead of petunidin. For this reason, three genetic models were proposed and tested. In all three models, a single hypothetical locus labeled $P$ was theorized to control the type of anthocyanidin (i.e., petunidin vs. cyanidin) produced. Plants with the $P P$ or $P p$ genotype were hypothesized to produce petunidin, whereas plants with the homozygous recessive genotype $p p$ produce cyanidin. In each model, $P P$ and $P p$ were assumed to be completely dominant to $p p$, as suggested by the pigment analysis of the $\mathrm{F}_{1} \mathrm{~s}$ of 'Peachies Pick' $\times$ 'Colorwheel' and $\mathrm{NC}$ Maroon $\times$ 'Honeysong Purple' (Table 1 and Fig. 1J). Based on these assumptions and previous observations, we proposed that the genotype for 'Peachies Pick' was $A A P P$ and the three possible genotypes for NC-Maroon and 'Colorwheel' were aapp (Model 1), Aapp (Model 2), or AApp (Model 3). Observed progeny from $\mathrm{F}_{1}, \mathrm{~F}_{2}$, and $\mathrm{BC}_{1}$ populations of 'Peachies Pick' $\times$
NC-Maroon and 'Colorwheel' were compared with the expected ratios as predicted by these three genetic models (Table 4) to determine the possible genotype(s) for NC-Maroon and 'Colorwheel'. Due to the inability to distinguish pale pinkfrom albescent-flowered progeny, expected genotypes as predicted by the three models were classified into two classes: $A-$ $P$ - plants with blue or purple flowers and $A-p p$, $a a P-$, and aapp: plants with albescent or pale pink flowers.

The $\mathrm{F}_{1} \mathrm{~s}$ of 'Peachies Pick' $\times$ NC-Maroon were lavender flowered as predicted by Model 1 (aapp), Model 2 (Aapp), and Model $3(A A p p)$. Flowers of $389 \mathrm{~F}_{2}$ plants were visually examined and partitioned into four phenotypic classes (228 blue or lavender, 57 purple, 40 albescent, and 64 pale pink), which were then grouped into two classes ( 285 blue, lavender, and purple: 104 albescent and pale pink) for analysis due to the difficulties in distinguishing between albescent- and pale pinkflowered progeny. This ratio was tested for goodness-of-fit to a 9:7 $\left(\chi^{2}=29.326, P=0.000\right)$ and 3:1 ratio $\left(\chi^{2}=0.625, P=0.429\right)$ as predicted by Models 1 and 3, respectively (Table 4). According to Model 2 (Aapp), two $\mathrm{F}_{1}$ progeny ( $1 / 2 A A P p$ and $1 / 2 A a P p)$ could be produced when Aapp is crossed with 'Peachies Pick' $(A A P P)$. Thus, the $\mathrm{F}_{2}$ bulk population produced by randomly intermating these $\mathrm{F}_{1} \mathrm{~s}(1 / 2 A A P p$ and $1 / 2 A a P p)$ would theoretically consist of progeny produced by three different crosses $(1 / 4 A A P p \times A A P p, 1 / 4 A a P p \times A a P p$, and $1 / 2$ $A A P p \times A a P p)$. Because each cross produces a different expected segregation ratio for blue + lavender + purple:albescent + pale pink progeny $(A A P p \times A A P p-3: 1, A a P p \times A a P p-$ 9:7, $A A P p \times A a P p-3: 1)$, the "average" expected ratio of the $\mathrm{F}_{2}$ bulk population is $45: 19$. The observed $F_{2}$ data were tested against the ratio of $45: 19\left(\chi^{2}=1.624, P=0.203\right)$, as suggested by Model 2 (Table 4 ), and were found to match more closely than Model $1\left(\chi^{2}=29.326, P=0.000\right)$, but not as closely as Model $3\left(\chi^{2}=0.625, P=0.429\right)$. These results indicate that the genotype of NC-Maroon is likely $A A p p$ as predicted by Model 3.

The $\mathrm{F}_{1} \mathrm{~s}$ of 'Peachies Pick' $\times$ 'Colorwheel' were lavender, as predicted by all three models. A total of $45 \mathrm{~F}_{2}$ plants were visually examined and placed into four phenotypic classes (28 blue or lavender, 3 purple, 1 albescent, and 13 pale pink), which were then combined into two classes ( 31 blue, lavender, and purple:14 albescent and pale pink) for analysis due to the aforementioned difficulties in distinguishing between pale pink- and albescent-flowered progeny. This ratio was tested for goodness-of-fit to a 9:7 $\left(\chi^{2}=2.921, P=0.087\right)$ and 3:1 ratio $\left(\chi^{2}=0.340, P=0.560\right)$ as predicted by Models 1 and 3 , respectively (Table 4 ). As with the previous example, Model 2 predicted that 'Colorwheel' with a genotype of Aapp when crossed with 'Peachies Pick' $(A A P P)$ produces two possible $\mathrm{F}_{1} \mathrm{~s}$ $(A A P p, A a P p)$ in equal numbers. Therefore, the bulked $\mathrm{F}_{2}$ population produced by these $\mathrm{F}_{1} \mathrm{~S}$ would theoretically consist of three different crosses that when averaged would equal a total of 45 blue, lavender, and purple: 19 albescent and pale pink progeny. These data were tested against the "averaged" expected ratio $\left(\chi^{2}=0.044, P=0.834\right)$ (Table 4$)$. Results indicate that the genotype of 'Colorwheel' is likely either Aapp as predicted by Model $2\left(\chi^{2}=0.044, P=0.834\right)$ or $A A p p$ as predicted by Model $3\left(\chi^{2}=0.340, P=0.560\right)$.

Two $\mathrm{BC}_{1}$ populations of 'Peachies Pick' $\times$ 'Colorwheel' segregated for five different colors: blue/lavender, purple, albescent, pale pink, and orchid. Orchid-flowered progeny had flowers that were mostly bluish-lavender with a subtle 
Table 4. Segregation of flower color in $\mathrm{F}_{2}$ and $\mathrm{BC}_{1}$ families of stokes aster. Blue and lavender flowers are phenotypically and biochemically similar, therefore, they were combined for analysis and designated as "blue." Due to the inability to distinguish pale pink and albescent progeny, progeny were grouped into two phenotypic classes (blue, lavender, violet, and orchid: albescent and pale pink) for analysis.

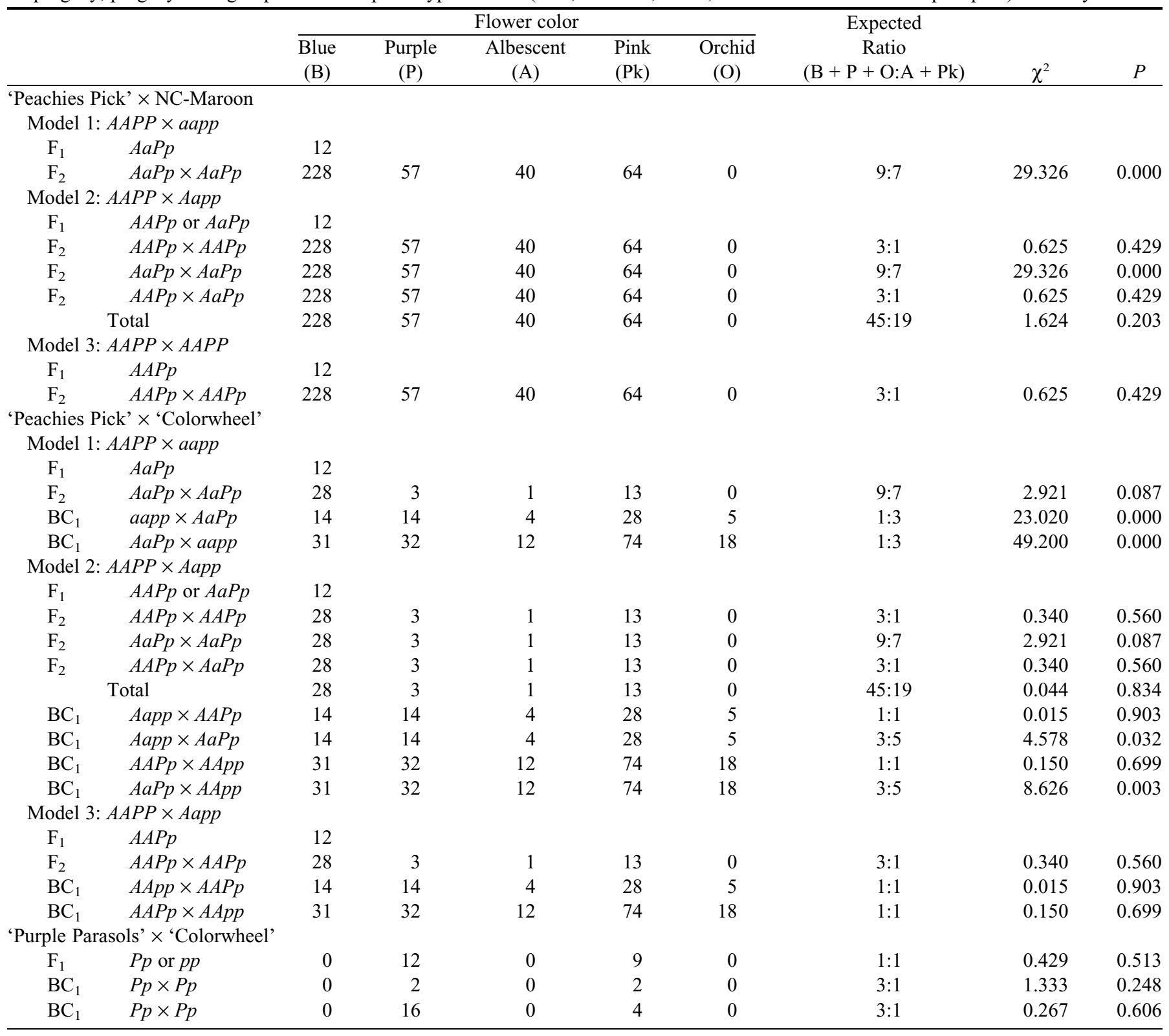

blush of pink and most closely resembled the blue and purple phenotypes, thus these progeny were grouped accordingly (blue, lavender, purple, and orchid:albescent and pale pink) for analysis. Segregation ratios of two $\mathrm{BC}_{1}$ populations were 14 blue/lavender:14 purple: 4 albescent:28 pink:5 orchid and 31 blue/lavender:32 purple:12 albescent:74 pink:18 orchid, respectively. These two populations were not combined for analysis because the $\mathrm{F}_{1} \mathrm{~s}$ were not clonal and according to Model 2 could have different genotypes ( $A A P p$ or $A a P p)$. The observed ratios were tested for fit to a 1:3 ratio $\left(\chi^{2}=23.020, P=\right.$ $0.000 ; \chi^{2}=49.200, P=0.000$ ) as predicted by Model 1 (Table 4). The observed ratios were also fit to $1: 1$ ratio $\left(\chi^{2}=0.015, P=\right.$ $0.903 ; \chi^{2}=0.150, P=0.699$ ) as predicted by Model 3 (Table 4 ). Because Model 2 predicted two equally possible $\mathrm{F}_{1} \mathrm{~s}(A A P p$ and $A a P p$ ), the two $\mathrm{BC}_{1}$ populations were compared with a 1:1 ratio $\left(\chi^{2}=0.015, P=0.903 ; \chi^{2}=0.150, P=0.699\right)$ as expected when an $\mathrm{F}_{1}$ had the $A A P p$ genotype, and were then compared with a $3: 5$ ratio $\left(\chi^{2}=4.578, P=0.032 ; \chi^{2}=8.626, P=0.003\right)$ as expected with an $\mathrm{F}_{1}$ with the $A a P p$ genotype (Table 4). The observed ratios from both $\mathrm{BC}_{1}$ populations did not fit Model 1 or Model 2 with an $\mathrm{F}_{1}$ with the $A a P p$ genotype, but they did fit the expected ratios predicted by Model 3 and Model 2, but only when an $\mathrm{F}_{1}$ with the AAPp genotype was used. Therefore, based on the findings from the $\mathrm{F}_{2}$ and $\mathrm{BC}_{1}$ populations, we conclude that the genotype for 'Colorwheel' is either Aapp as predicted by Model 2 with an Aapp $\mathrm{F}_{1}$ plant used in the $\mathrm{BC}_{1}$ crosses or AApp as predicted by Model 3.

$\mathrm{F}_{1} \mathrm{~s}$ of 'Purple Parasols' $\times$ 'Colorwheel' were one-half violet and one-half pale pink $\left(\chi^{2}=0.429, P=0.513\right)$. Two $\mathrm{BC}_{1}$ populations using a purple-flowered $F_{1}$ fit the expected ratio of 
$3: 1$ violet and pale pink $\left(\chi^{2}=1.333, P=0.248 ; \chi^{2}=0.267, P=\right.$ 0.606 ; Table 4). These results indicate that 'Purple Parasols' is heterozygous for $P$.

\section{Proposed biochemical pathway}

At least three major loci $(A, Y$, and $P)$ determine flower color in stokes aster. In a wild-type plant $(A-Y-P-)$ with blue, lavender, or violet flowers, two end-products are produced: one anthocyanidin (petunidin) and one copigment aglycone (luteolin). If we assume that the formation of flavonoids in this species follows the general biosynthetic pathway found in most plants, then the pigment profiles of the recessive mutants $(y y-$ 'Mary Gregory,' $p p$ - 'Colorwheel' and NC-Maroon indicate the possible steps (i.e., structural enzymes) of the biosynthetic pathway that are likely affected by these loci (Fig. 3). It is also possible that one or more of the loci $(A, Y$, or $P$ ) are not structural genes, but regulatory genes that influence the expression of those structural genes indicated as control points in Fig. 3. In either instance, the specific regions of the pathway likely controlled by $A, Y$, and $P$ are indicated in Fig. 3 .

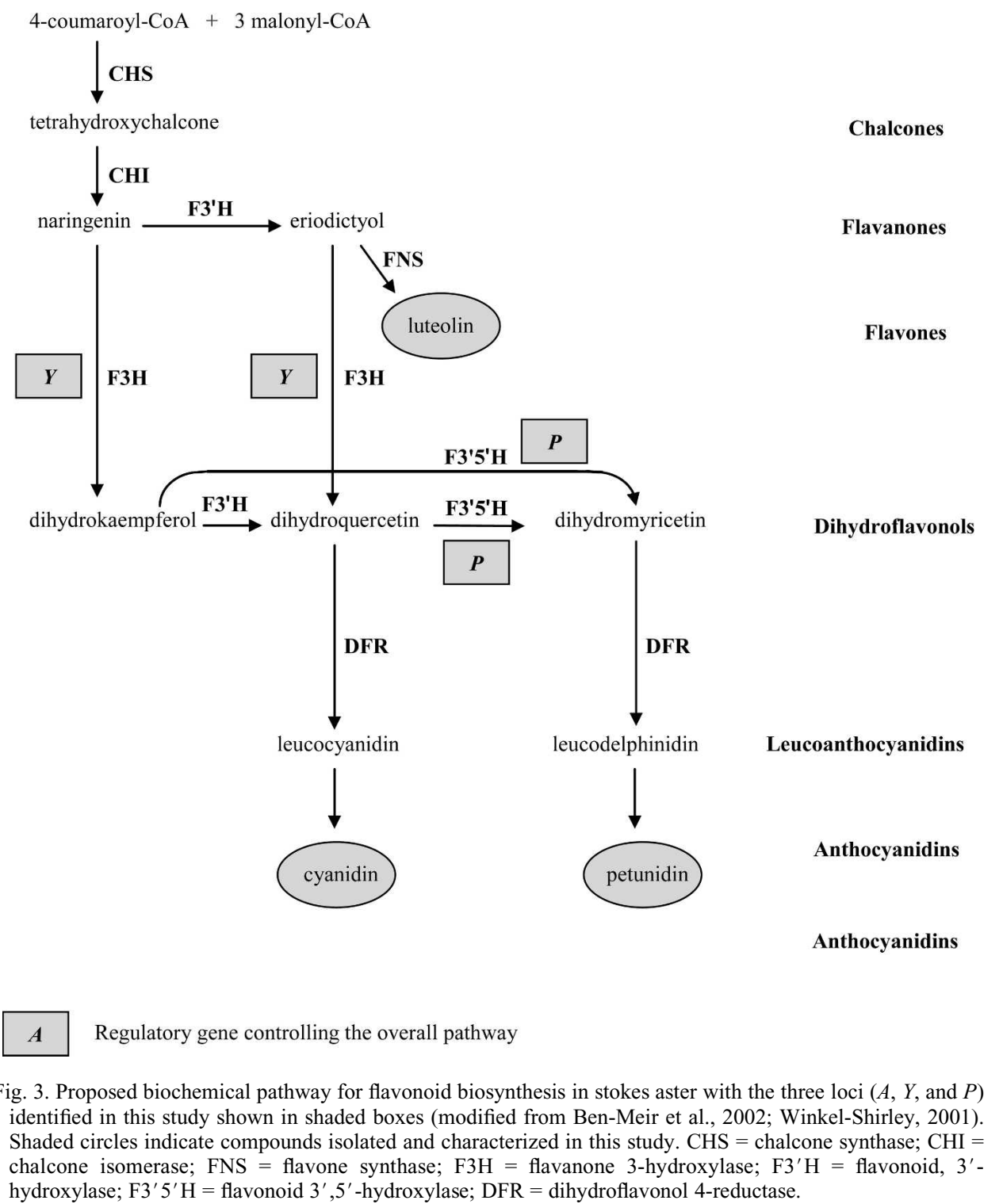

Dihydroflavonol 4-reductase (DFR) reduces dihydroflavonols to colorless leucoanthocyanidins, which are precursors to anthocyanidins. Substrate specificity of DFR is variable. DFR from Gerbera L., Matthiola (L.) R.Br., and Dianthus L. is active with a range of substrates [e.g., dihydromyricetin (DHM), dihydrokaempferol (DHK), dihydroquercetin (DHQ)] (Freyre and Griesbach, 2004; Helariutta et al., 1993; Heller et al., 1985; Holton and Cornish, 1995; Johnson et al., 2001; Stich et al., 1992). In contrast, DFR in other species is more specific. For example, in Petunia $\times$ hybrida Vilm. and Cymbidium Swartz, DFR does not efficiently reduce DHK (Forkmann and Ruhnau, 1987; Holton and Cornish, 1995; Johnson et al., 1999), and in Ipomea quamoclit L. the ability of DFR to metabolize DHQ is dramatically reduced relative to DHK (Zufall and Rausher, 2004). We propose that DFR in stokes aster has a strong preference for DHM relative to DHK and DHQ. This model predicts that wild-type flowers of stokes aster contain petunidin (DHM precursor), that cyanidin (DHQ precursor) mutants are possible, and that pelargonidin is not found in flowers of this species.

In stokes aster, flowers of the pale yellow, acyanic mutant only contain luteolin, while wild-type cyanic flowers contain luteolin and anthocyanins. This observation suggests that $y y$ mutants lack enzyme activity after the formation of flavanones and flavones (Fig. 3). We propose that in stokes aster, the enzyme flavanone 3-hydroxylase (F3H), which catalyzes the hydroxylation of flavanones (e.g., naringenin, eriodictyol, and pentahydroxyflavanon) to dihydroflavonols (e.g., DHK, DHQ, and DHM) is encoded by $Y$. Furthermore, the formation of luteolin in cyanic taxa ( $Y Y$ or $Y-$ ) suggests that luteolin is normally synthesized and is not simply an accumulation product found only in acyanic taxa (yy mutants). This effect is seen in other species where yellow pigments are normally produced but their presence is not obvious until anthocyanin biosynthesis is blocked by a natural mutation or by antisense suppression (Tyrach and Horn, 1997; Zuker et al., 2002). Although many genes associated with flavonoid biosynthesis (e.g., chalcone synthase and chalcone isomerase) have multiple copies, F3H (FHT in Dianthus) is a single-copy gene in Petunia xhybrida, Dianthus caryophyllus L., Callistephus chinensis (L.) Nees, Rosa hybrida L., Matthiola incana, (L.) R.Br., and Arabidopsis thaliana (L.) Heynh. (BenMeir et al., 2002; Bohm, 1998; Britsch et al., 1992; Dedio et al., 1995). Thus, it is not unreasonable 
to theorize that a single locus (i.e., $Y$ ) encodes $\mathrm{F} 3 \mathrm{H}$ in stokes aster.

Pale pink-flowering mutants of stokes aster contain cyanidin instead of petunidin. We propose that the locus encoding flavonoid $3^{\prime}, 5^{\prime}$-hydroxylase $\left(\mathrm{F}^{\prime} 5^{\prime} \mathrm{H}\right)$, which catalyzes the $3^{\prime}, 5^{\prime}$-hydroxylation of DHQ to form DHM, has two alleles that correspond to the two alleles at the $P$ locus identified in this study (Fig. 3). We theorize that the $P$ allele produces a functional form and the $p$ allele produces a nonfunctional form of F3' 5' H. Thus, $p p$ mutants of stokes aster that have pale pink flowers do not produce DHM, which is a required precursor for the synthesis of petunidin and consequently produce cyanidin from DHQ instead. Because DFR in stokes aster, which reduces dihydroflavonols to leucoanthocyanidins, is presumed to have a lower preference for DHQ relative to DHM (see previous paragraph), the total synthesis of cyanidin is expected to be reduced. This effect thus explains why the color of flowers containing cyanidin (pale pink) appear less saturated than flowers containing petunidin (blue, lavender, and violet; data not shown). Alternatively, the form of DFR in the $p p$ mutants could be functional but have a significantly higher affinity for DHQ versus DHM, which would produce flowers with mostly cyanidin and a trace of petunidin.

Albescent mutants that have a substantially reduced level of pigmentation compared with the wild type often have mutations that affect regulatory or structural genes controlling anthocyanin biosynthesis (Griesbach and Klein, 1993). Based on our results and the generalizations made concerning alba versus albescent mutants, we propose that $A$ is likely a regulatory gene that directs anthocyanin biosynthesis in stokes aster such that $A$ permits the wild type synthesis and accumulation of anthocyanins (petunidin and cyanidin) and copigments (luteolin), whereas the mutant form, $a$, reduces the synthesis or prevents the accumulation of both compounds.

\section{Conclusions}

Although there is uncertainty in assigning genotypes to plants that cannot be inbred to homozygosity, the evidence presented in this study accounts for the discrete segregations that were observed. Based on these results, we determined that at least three loci $(A, P$, and $Y$ ) control flower color in stokes aster: $A$ permits the normal synthesis of anthocyanins and other flavonoids, and $a$ reduces the synthesis or prevents the accumulation of anthocyanins and other flavonoids; $Y$ permits the normal synthesis of anthocyanins, and $y$ completely blocks the synthesis of anthocyanins; $P$ produces petunidin, and $p$ produces cyanidin. All three loci are completely dominant, and $Y$ in the homozygous recessive state $(y y)$ is epistatic to $A$ and $P$. Based on our biochemical and genetic analyses, we propose the following genotypes: 'Peachies Pick': $A A P P Y Y$, 'Alba': aaP$P Y Y$, 'Mary Gregory': AAPPyy and NC-Maroon: AappYY and 'Colorwheel': either $A A p p Y Y$ or AappYY, and 'Purple Parasols': $A A P p Y Y$.

\section{Literature Cited}

Bailey, L.H. 1949. Manual of cultivated plants. Revised ed.. Macmillan, New York.

Ben-Meir, H., A. Zuker, D. Weiss, and A. Vainstein. 2002. Molecular control of floral pigmentation: Anthocyanins, p. 253-272. In: A. Vainstein (ed.). Breeding for ornamentals: Classical and molecular approaches. Kluwer Academic Publishers, Dordrecht, The Netherlands.
Bohm, B.A. 1998. Introduction to flavonoids. Harwood Academic, Amsterdam, The Netherlands.

Bohm, B.A. and T.F. Stuessy. 2001. Flavonoids of the sunflower family (Asteraceae). Springer-Verlag, Vienna, Austria.

Britsch, L., B. Ruhnau-Brich, and G. Forkmann. 1992. Molecular cloning, sequence analysis, and in vitro expression of flavanone $3 \beta$ hydroxylase from Petunia hybrida. J. Biol. Chem. 267(8):53805387.

Chandler, S.F. and C. Lu. 2005. Biotechnology in ornamental horticulture. Vitro Cell. Biol. Plant 41:591-601.

Conner, P. and H.T. Erickson. 1991. Inheritance of corolla striping and flower colors in Salpiglossis sinuata. HortScience 26(12):15491550 .

Courtney-Gutterson, N. 1994. The biologist's palette: Genetic engineering of anthocyanin biosynthesis and flower color, p. 93124. In: B.E. Ellis, G.W. Kuroki, and H.A. Staffordt (eds.). Genetic engineering of plant secondary metabolism. Plenum Press, New York.

Davies, K.M. and K.E. Schwinn. 1997. Flower colour, p. 259-294. In: R.L. Geneve, J.E. Preece, and S.A. Merkle (eds.). Biotechnology of ornamental plants. CAB International, New York.

Dedio, J., H. Saedler, and G. Forkmann. 1995. Molecular cloning of the flavanone $3 \beta$-hydroxylase gene (FHT) from carnation (Dianthus caryophyllus) and analysis of stable and unstable FHT mutants. Theor. Appl. Genet. 90:611-617.

Fick, G.N. 1976. Genetics of floral color and morphology in sunflowers. J. Hered. 67:227-230.

Forkmann, G. 1991. Flavonoids as flower pigments: The formation of the natural spectrum and its extension by genetic engineering. Plant Breed. 106:1-26.

Forkmann, G. and S. Martens. 2001. Metabolic engineering and applications of flavonoids. Curr. Opin. Biotechnol. 12:155-160.

Forkmann, G. and B. Ruhnau. 1987. Distinct substrate specificity of dihydroflavonol 4-reductase from flowers of Petunia hybrida. Zeitschrift für Naturforschung 42:1146-1148.

Freyre, R. and R.J. Griesbach. 2004. Inheritance of flower color in Anagallis monelii L. HortScience 39(6):1220-1223.

Gerats, A.G.M. and C. Martin. 1992. Flavonoid synthesis in Petunia hybrida Genetics and molecular biology of flower color, p. 165-199. In: H.A. Stafford and R.K. Ibrahim (eds.). Phenolic metabolism in plants. Plenum Press, New York.

Gettys, L.A. 2000. Investigations of optimum seed germination conditions, reproductive biology, and genetic relationships between cultivars of stokes aster [Stokesia laevis (J. Hill) Greene]. MS thesis. North Carolina State University, Raleigh.

Gettys, L.A. and D.J. Werner. 2002. Stokes aster. HortTechnology 12(1):138-142.

Gould, K.S. 2004. Nature's Swiss army knife: The diverse protective roles of anthocyanins in leaves. J. Biomed. Biotechnol. 2004(5):314320.

Griesbach, R.J. 1997. The biochemical basis for the blue flower color mutations in Doritis pulcherrima and Phalaenopsis violacea. Lindleyana 12(2):64-71.

Griesbach, R.J. 2005. Biochemistry and genetics of flower color. Plant Breed. Rev. 25:89-114.

Griesbach, R.J. and S. Asen. 1990. Characterization of the flavonol glycosides in Petunia. Plant Sci. 70:49-56.

Griesbach, R.J., S. Asen, and B.A. Leonnarat. 1991. Petunia hybrida anthocyanins acylated with caffeic acid. Phytochemistry 30(5):1729-1731.

Griesbach, R.J. and L. Batdorf. 1995. Flower pigments within Hemerocallis fulva L. fm. Fulva, fm. Rosea, and fm. Disticha. HortScience 30(2):353-354.

Griesbach, R.J. and T.M. Klein. 1993. In situ genetic complementation of a flower color mutant in Doritis pulcherrima (Orchidaceae). Lindleyana 8(4):223-226.

Gunn, C.R. and G.A. White. 1974. Stokesia laevis: Taxonomy and economic value. Econ. Bot. 28:130-135. 
Harborne, J.B. 1978. The rare flavone isoetin as a yellow flower pigment in Heywoodiella oligocephala and in other Cichorieae. Phytochemistry 17:915-917.

Harborne, J.B. 1991. Revised structures for three isoetin glycosides, yellow flower pigments in Heywoodiella oligocephala and in other Cichorieae. Phytochemistry 30(5):1677-1678.

Harborne, J.B. and C.A. Williams. 1977. Vernonieae: Chemical review, p. 524-534. In: V.H. Heywood, J.B. Harborne, and B.L. Turner (eds.). The biology and chemistry of the Compositae. Academic Press, New York.

Harborne, J.B. and C.A. Williams. 2000. Advances in flavonoid research since 1992. Phytochemistry 55:481-504.

Hawkins, L.K. and F. Dane. 2001. Molecular markers associated with morphological traits in watermelon. HortScience 36(7):1318-1322.

Helariutta, Y., M. Kotilainen, P. Seppanen, and T.H. Teeri. 1993. Cloning of cDNA coding for dihydroflavonol-4-reductase (DFR) and characterization of $d f r$ expression in the corollas of Gerbera hybrida var. Regina (Compositae). Plant Mol. Biol. 22:183-193.

Heller, W., G. Forkmann, L. Britsch, and H. Griesbach. 1985. Enzymatic reduction of (+)-dihydroflavonols to flavan-3,4-cis-diols with flower extracts from Mattiola incana and its role in anthocyanin biosynthesis. Planta 165:284-287.

Holton, T.A. and E.C. Cornish. 1995. Genetics and biochemistry of anthocyanin biosynthesis. Plant Cell 7:1071-1083.

Johnson, E.T., H. Yi, B. Shin, B. Oh, H. Cheong, and G. Choi. 1999. Cymbidium hybrida dihydroflavonol 4-reductase does not efficiently reduce dihydrokaempferol to produce orange pelargonidin-type anthocyanins. Plant J. 19(1):81-85.

Johnson, E.T., S. Ryu, H. Yi, B. Shin, H. Cheong, and G. Choi. 2001. Alteration of a single amino acid changes the substrate specificity of dihydroflavonol 4-reductase. Plant J. 25(3):325-333.

Jones S.B.,, Jr. 1974. Vernonieae (Compositae) chromosome numbers. Bul. Torrey Bot. Club 101(1):31-34.

Markham, K.R., K.S. Gould, and K.G. Ryan. 2001. Cytoplasmic accumulation of flavonoids in flower petals and its relevance to yellow flower colouration. Phytochemistry 58:403-413.

Mol, J., E. Cornish, J. Mason, and R. Koes. 1999. Novel coloured flowers. Curr. Opin. Biotechnol. 10:198-201.

Nau, J. 1996. Ball perennial manual: Propagation and production. Ball Publishing, Batavia, IL.

Noda, K., B.J. Glover, P. Linstead, and C. Martin. 1994. Flower color intensity depends on specialized cell-shape controlled by a MYBrelated transcription factor. Nature 369:661-664.
Pahlavani, M.H., A.F. Mirlohi, and G. Saeidi. 2004. Inheritance of flower color and spininess in safflower (Carthamus tinctorius L.). J. Hered. 95(3):265-267.

Schijlen, E.G.W.M., C.H. Ric de Vos, A.J. van Tunen, and A.G. Bovy. 2004. Modification of flavonoid biosynthesis in crop plants. Phytochemistry 65:2631-2648.

Shiono, M., N. Matsugaki, and K. Takeda. 2005. Structure of the blue cornflower pigment. Nature 436:791.

Steyn, W.J., S.J.E. Wand, D.M. Holcroft, and G. Jacobs. 2002. Anthocyanins in vegetative tissues: A proposed unified function in photoprotection. New Phytol. 155:349-361.

Stich, K., T. Eidenberger, F. Wurst, and G. Forkmann. 1992. Enzymatic conversion of dihydroflavonols to flavan-3,4-diols using flower extracts of Dianthus caryophyllus L. (carnation). Planta 187:103-108.

Still, S.M. 1994. Manual of herbaceous ornamental plants. 4th ed. Stipes Publishing, Champaign, IL.

Strickberger, M.W. 1976. Genetics. 2nd ed. Macmillan, New York.

Tanaka, Y., Y. Katsumoto, F. Brugliera, and J. Mason. 2005. Genetic engineering in floriculture. Plant Cell Tissue Organ Cult. 80:1-24.

Tyrach, A. and W. Horn. 1997. Inheritance of flower color and flavonoid pigments in Gerbera. Plant Breed. 116:377-381.

Waterworth, R.A. and R.J. Griesbach. 2001. The biochemical basis for flower color in Calibrachoa. HortScience 36(1):131-132.

Wiering, H. and P. de Vlaming. 1984. Inheritance and biochemistry of pigments, p. 49-76. In: K.C. Sink (ed.)Petunia. Springer-Verlag, Berlin.

Winkel-Shirley, B. 2001. Flavonoid biosynthesis. A colorful model for genetics, biochemistry, cell biology, and biotechnology. Plant Physiol. 126:485-493.

Winkel-Shirley, B. 2002. Biosynthesis of flavonoids and effects of stress. Curr. Opin. Plant Biol. 5:218-223.

Yabuya, T., M. Saito, T. Iwashina, and M. Yamaguchi. 2000. Stability of flower colors due to anthocyanin-flavone copigmentation in japanese garden iris, Iris ensata Thunb. Euphytica 15:1-5.

Zufall, R.A. and M.D. Rausher. 2004. Genetic changes associated with floral adaptation restrict future evolutionary potential. Nature 428:847-850.

Zuker, A., T. Tzfira, H. Ben-Meir, M. Ovadis, E. Shklarman, H. Itzhaki, G. Forkmann, S. Martens, I. Neta-Sharir, D. Weiss, and A. Vainstein. 2002. Modification of flower color and fragrance by antisense suppression of the flavanone 3-hydroxylase gene. Mol. Breed. 9:33-41. 